\title{
Effects of Endodontic Access Cavity Design and Thermocycling on Fracture Strength of Endodontically Treated Teeth
}

This article was published in the following Dove Press journal:

Clinical, Cosmetic and Investigational Dentistry

\author{
Eshagh Ali Saberi $\mathbb{D}^{\prime}$ \\ Arezoo Pirhaji ${ }^{2}$ \\ Fatemeh Zabetiyan ${ }^{3}$ \\ 'Department of Endodontics, Faculty of \\ Dentistry, Oral and Dental Diseases \\ Research Center, Zahedan University of \\ Medical Sciences, Zahedan, Iran; \\ ${ }^{2}$ Department of Endodontics, Faculty of \\ Dentistry, Zahedan University of Medical \\ Sciences, Zahedan, Iran; ${ }^{3}$ General \\ Dentistry, Mashhad University of Medical \\ Sciences, Mashhad, Iran
}

\begin{abstract}
Introduction: This study aimed to assess the fracture strength of endodontically treated mandibular molars with traditional endodontic access cavity (TEC) and truss endodontic access cavity (TREC) designs that were restored with composite resin and underwent thermocycling.
\end{abstract}

Methods: Sixty mandibular first and second molars were randomly divided into 6 groups $(\mathrm{n}=10)$ of intact controls without thermocycling (group 1), intact controls with thermocycling (group 2), TEC without thermocycling (group 3), TEC with thermocycling (TEC-TC, group 4), TREC without thermocycling (group 5) and TREC with thermocycling (TRECTC, group 6). The root canals were then instrumented to $\# 25,7 \%$ using nickel-titanium files and were filled with gutta-percha and AH26 sealer with lateral compaction technique. Access cavity was restored with Gradia composite. All teeth were then thermocycled for 480 cycles between $5^{\circ} \mathrm{C}$ and $55^{\circ} \mathrm{C}$ for 30 seconds and their fracture strength was measured in a universal testing machine with a round-end piston with $6 \mathrm{~mm}$ diameter at a speed of $1 \mathrm{~mm} / \mathrm{min}$. Data were analyzed using two-way and one-way ANOVA.

Results: Without thermocycling, the fracture strength of endodontically treated teeth with TREC designs had no significant difference with the control group $(\mathrm{P}>0.05)$. However, both TEC and TREC designs significantly decreased the fracture strength of endodontically treated teeth after thermocycling $(\mathrm{P}<0.05)$, such that minimum fracture strength was noted in TEC-TC group

Conclusion: Under the conditions of this ex vivo study, TREC enhances the fracture strength of endodontically treated teeth under thermal stresses.

Keywords: endodontic cavity, fracture strength, minimally invasive intervention

\section{Introduction}

The fracture strength of endodontically treated teeth is lower than that of vital teeth. This difference may be due to the dentin hardness of vital teeth, which is higher than that of endodontically treated teeth. ${ }^{1}$ However, reconstruction of structure, esthetics and function of endodontically treated teeth is associated with some problems, ${ }^{2}$ which can be due to the significant reduction of their tooth structure (dentin) during access cavity preparation that decreases their fracture strength in function. ${ }^{3,4}$

In conventional or traditional endodontic access cavity (TEC) preparation, the tooth structure is removed in a controlled manner to prevent endodontic complications. ${ }^{5}$ However, loss of dentin and anatomical structures such as cusps,
Correspondence: Eshagh Ali Saberi Department of Endodontics, Faculty of Dentistry, Azadegan Street, Zahedan, Iran Tel +989151416924

Email saberiendo@yahoo.com 
marginal ridges and pulp chamber floor can lead to tooth fracture after final restoration. ${ }^{6,7}$ Unlike TEC, the truss endodontic access cavity (TREC) design is less invasive and preserves parts of the tooth structure such as the pericervical dentin, and can improve the fracture strength of endodontically treated teeth. ${ }^{8-11}$ However, the influence of access cavity design on fracture resistance has not been well elucidated and remains controversial. ${ }^{12,13}$

Attempts are ongoing to offer more conservative access cavity designs. The currently suggested conservative access cavity designs include the contracted design (a small conservative access cavity in the occlusal surface that allows the clinician to access all canal orifices), the truss design (direct access from the occlusal surface to expose mesial and distal canal orifices while preserving the intact dentinal bridge between the orifices), and the ninja design (ultraconservative approach). These designs have been proposed to enhance the fracture strength of endodontically treated teeth and decrease the dependence of the tooth on complex and high-cost postendodontic restorations. ${ }^{14-17}$

Evidence shows that the primary canal curvature parameters are not significantly different between the TEC and contracted access cavity design; however, duration of instrumentation significantly increases in the latter. ${ }^{18}$ Nonetheless, evidence shows that the truss access cavity design increases the fracture strength of endodontically treated teeth. ${ }^{19}$ Moreover, ultraconservative endodontic cavities were not associated with an increase in fracture resistance of endodontically treated two-rooted maxillary premolars. ${ }^{13}$

Thermocycling is commonly used in vitro to simulate in vivo aging by use of hot and cold bathes. It simulates the thermal alterations in the oral cavity to better simulate the clinical setting. ${ }^{20}$ However, none of the recent studies on this topic have performed thermocycling.

Since all relevant previous studies assessed TEC or TREC without simulation of in vivo conditions (for example, by thermocycling), this study aimed to assess the fracture strength of endodontically treated mandibular molars with TEC and TREC designs restored with composite resin after thermocycling. The null hypothesis tested was that there would be no influence of the tested treatment modalities on fracture strength of endodontically treated mandibular molars.

\section{Materials and Methods}

In this ex vivo study, ethical approval was obtained from Zahedan University of Medical Sciences (IR.ZAUMS. REC.1395.243). Sample size was calculated to be 10 in each group according to previous studies, ${ }^{6,21}$ assuming alpha $=0.05$, beta $=0.2$ and study power of $80 \%$.

Sixty mandibular first and second molars with mature apices belonging to patients between 20 and 60 years were collected after obtaining written informed consent from the patients. The teeth had no visible carious lesion, restoration, crack or fracture. After debriding the tooth surface using hand scaling instruments and cleaning the root and crown surfaces with a rubber cup and pumice paste, the teeth were stored in $0.9 \%$ saline at $4^{\circ} \mathrm{C}$ until the experiment and during different phases of intervention to prevent dehydration. Maximum storage time was 6 months. All teeth underwent digital radiography from the buccolingual and mesiodistal directions using a posterior film holder (Dentsply DeTrey GmbH, Konstanz, Germany) customized by putty impression material (Spidex, Asia Chemi Teb Mfg Co. Tehran, Iran). The anatomic crown height from the occlusal surface to the cementoenamel junction in all four surfaces was measured. The buccolingual and mesiodistal dimensions of the teeth were measured from the occlusal surface using a digital caliper (Digimatic 500; Mitutoyo, Kanagawa, Japan). The mean mesiodistal and buccolingual pulp chamber distances were $3.81 \mathrm{~mm}$ and $4.48 \mathrm{~mm}$, respectively, and the mean distance between the occlusal surface and the pulp chamber roof was $4.20 \mathrm{~mm}$ in the selected teeth.

The teeth were then randomly divided into four experimental $(\mathrm{n}=10)$ and two control groups as follows:

Group 1: Intact control group without thermocycling $(\mathrm{CON})$

Group 2: Intact control group with thermocycling (CON-TC)

Group 3: Traditional endodontic access cavity without thermocycling (TEC)

Group 4: Traditional endodontic access cavity with thermocycling (TEC-TC)

Group 5: Truss endodontic access cavity without thermocycling (TREC)

Group 6: Truss endodontic access cavity with thermocycling (TREC-TC)

Teeth with almost similar shape and size were allocated to each group for the purpose of standardization and in order to minimize the effect of variable sizes and shapes of the teeth on the results. ${ }^{21}$

\section{Preparation of TEC and TREC Designs}

Access cavities were prepared in all experimental groups using a diamond bur (No. 856; Intensiv SA, Switzerland) 


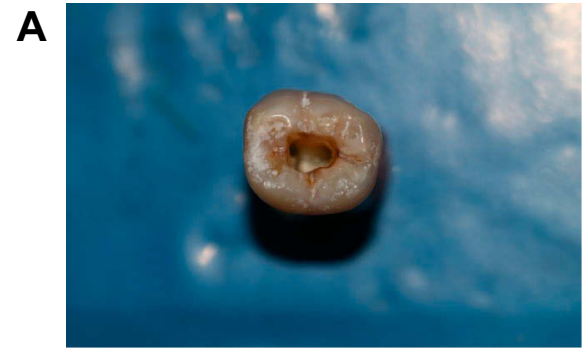

Figure I Teeth with TEC (A) and TREC (B) designs.

and high-speed hand-piece under air and water coolant. Preparation of TEC was started from the mesial part of the central fossa and continued towards the apical and distal to completely eliminate the pulp chamber roof. After completion of TEC preparation, the canal orifices were completely visible (Figure 1).

The TREC was prepared by preserving part of the pulp chamber roof. For this purpose, a Williams periodontal probe was used to measure the distance from the marginal ridges and the buccal and lingual surfaces to the pulp chamber floor on radiographs. The margins were extended to the occlusal surface to serve as a guide for straight introduction of bur into the canal orifices. Next, separate round access cavities were created for accessing the mesial canals in buccal and lingual directions. Another round access cavity was created to access the orifice of the distal canal. The separate round mesial access cavities were then
B

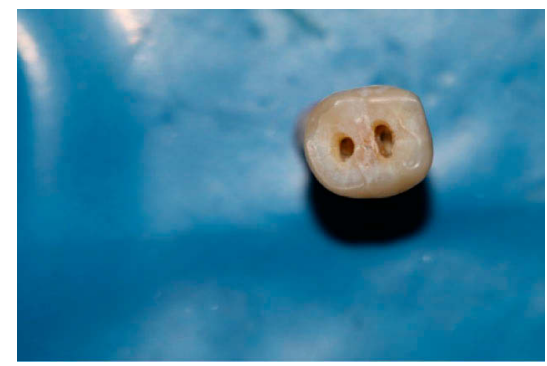

merged to form an oval-shaped access cavity with a minimum diameter of $1.2 \mathrm{~mm}$. The round access cavity of the distal canal was flared while preserving its round shape to reach $1.2 \mathrm{~mm}$ diameter (measured by a digital caliper). The mesial and distal access cavities on the occlusal surface had been separated by a dentin-enamel bridge. (Figures 1 and 2). ${ }^{18}$ We tried our best to standardize the dimensions and depth of the access cavity in all teeth of the groups. Samples that did not meet these criteria were excluded and replaced.

\section{Endodontic Treatment}

After access cavity preparation, a \#15 K-file was introduced into the canal and reached the apical foramen. After observing the file tip at the apical foramen, $1 \mathrm{~mm}$ was subtracted from this length to determine the working length. The root canals were filed to D4 (\#25, 7\%) using
A

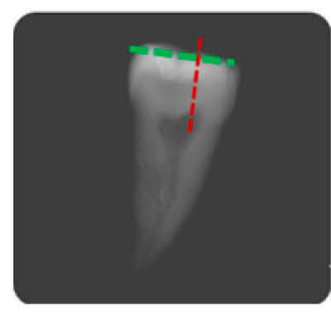

B

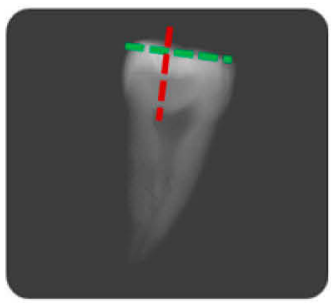

C

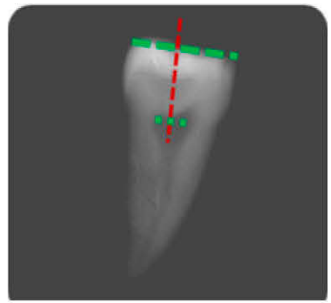

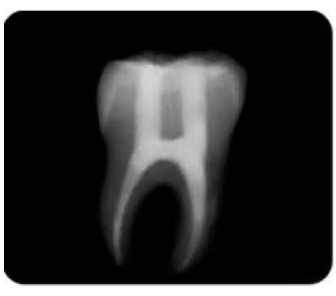

G

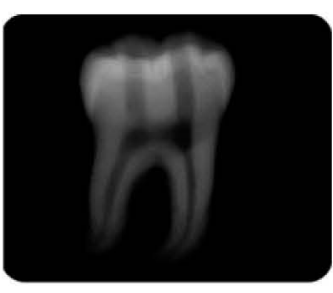

F

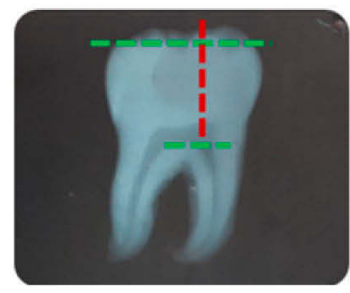

E

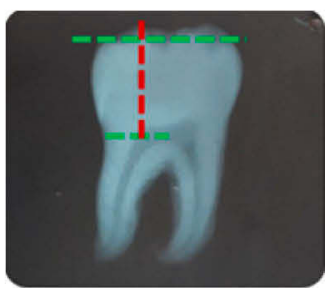

D

Figure 2 Determining the location and path of accessing the root canals through a TREC on the mesial and distal (A-C) and buccal and lingual (D and E) radiographs. The distance between the buccal and lingual surfaces of the teeth and also the distance between the mesial and distal surfaces of the teeth were determined (green and red dotted lines) and the perpendicular path to the occlusal surface was estimated to access the mesial and distal canal orifices such that the enamel-dentin bridge between the two access cavities was preserved. $\mathbf{F}$ shows the TREC access cavity and $\mathbf{G}$ shows the obturated canal along with a restored access cavity. 
Dia-PT nickel-titanium file system (DPT; Dia-Dent, Cheongwon, Korea) according to the manufacturer's instructions. The canals were rinsed with $5.25 \%$ sodium hypochlorite, and the smear layer was removed.

After drying of the root canals with paper points, they were filled with gutta-percha (Dentplus, Dia-Dent Group International, Korea) and AH26 sealer (Dentsply, De Trey). The sealer was mixed according to the manufacturer's instructions and delivered into the canal using a Lentulo spiral. Next, a conventional \#25 gutta-percha master cone was dipped in sealer and gently placed in the canal. The canals were obturated by spreader-accessory cone combination. Excess gutta-percha was removed by a heat carrier at the canal orifice. The remaining guttapercha was packed in the canals, and the access cavity was cleaned with ethyl alcohol. Eventually, the access cavities were restored.

\section{Restoration of Teeth}

Except for the control group, all the enamel and dentinal walls (including the beveled area) were etched with $37 \%$ phosphoric acid gel (Morva Etch, Tehran, Iran) for $30 \mathrm{~s}$ for the enamel and $15 \mathrm{~s}$ for the dentin. The samples were washed for $30 \mathrm{~s}$ and dried with absorbent paper followed by the application of 2 layers of bonding agent (Ultimate Bond; Master-Dent, USA). Gentle air blast was applied for $5 \mathrm{~s}$ to evaporate the adhesive solvent followed by $10 \mathrm{~s}$ of light curing by a LED curing unit. The access cavities were restored with composite resin (Gradia Direct, Japan). Composite was applied by the oblique incremental technique intercalated with $40 \mathrm{~s}$ of light curing to the level of the occlusal surface with preservation of the occlusal anatomy.

\section{Simulation of Periodontal Ligament}

The root canals were coated with wax from the root apex to the cementoenamel junction. Next, they were mounted in a metal mold containing auto-polymerizing acrylic resin (Acropars, Tehran, Iran) to the level of their cementoenamel junction. In order to eliminate the heat generated by the polymerization reaction of resin, the crowns remained hydrated by constant water spray. After acrylic polymerization, the teeth were removed from the acrylic and the wax was removed with hot water. To simulate the periodontal ligament, the created space was filled with silicon light body (wash) impression material (Speedex, Asia Chemi Teb Mfg Co., Iran) and the teeth were embedded in it to the level of their cementoenamel junction. The teeth were then stored in $0.9 \%$ saline solution at $4^{\circ} \mathrm{C}$ until measuring their fracture strength. The duration of storage was minimally 24 hours and maximally 36 hours. A parallelometer was used to position the longitudinal axis of the tooth perpendicular to the ground. The samples then underwent thermocycling with the following protocol.

\section{Thermocycling}

All teeth in the control, TEC and TREC groups were stored in distilled water with no additional treatment. The teeth in CON-TC, TEC-TC, and TREC-TC groups underwent 480 thermal cycles between $5^{\circ} \mathrm{C}$ and $55^{\circ} \mathrm{C}$ with a dwell time of $30 \mathrm{~s}$ and transfer time of $5 \mathrm{~s}$ in a thermocycler (Nemo, Iran). The teeth then underwent fracture strength test.

\section{Fracture Strength Testing}

Prior to testing, all teeth were stored in distilled water at room temperature $\left(25^{\circ} \mathrm{C}\right)$ for 24 hours. Next, all teeth were subjected to load application to their central fossa along their lingual surface with $15^{\circ}$ angle relative to their longitudinal axis in an Instron universal testing machine (Load Cell 20, Santam, Iran). Load was applied by a round-end piston with $6 \mathrm{~mm}$ diameter at a crosshead speed of $1 \mathrm{~mm} /$ min until tooth fracture (Figure 3). The load at fracture was recorded in Newtons $(\mathrm{N})$ for each tooth.

\section{Statistical Analysis}

Data were analyzed using SPSS version 22 (SPSS Inc., IL, USA). Normal distribution of data was evaluated using the Anderson-Darling test. Two-way ANOVA was applied to assess the effects of access cavity design and thermocycling, and their interaction effect on fracture strength of the teeth. Also, one-way ANOVA and Duncan's test were used for the comparison of the groups, and $t$-test was applied to analyze the effect of thermocycling on fracture strength and compare the groups in this respect at $\mathrm{p}<0.05$ level of significance.

\section{Results}

The Anderson-Darling test showed normal distribution of data. Two-way ANOVA revealed significant effects of access cavity design with thermocycling on fracture strength of endodontically treated teeth $(\mathrm{p}<0.05)$.

One-way ANOVA and Duncan's test revealed that although thermocycling had no significant effect on fracture strength of the control groups (without access cavity), it significantly decreased the fracture strength of teeth with 


\section{A control}
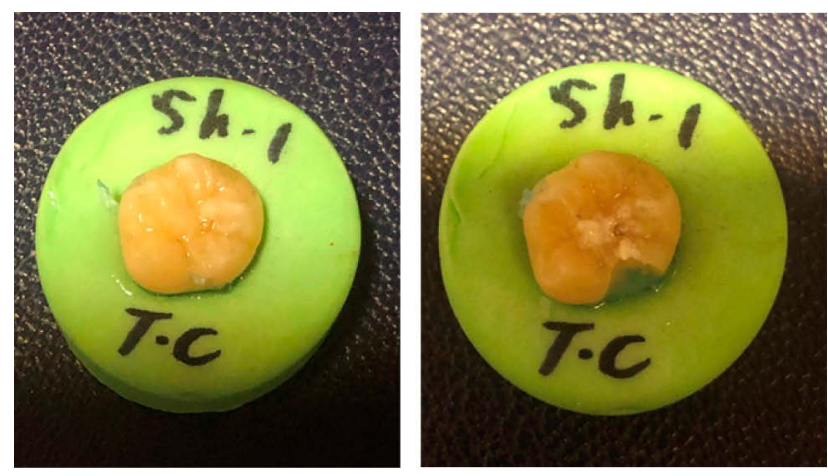

B TEC
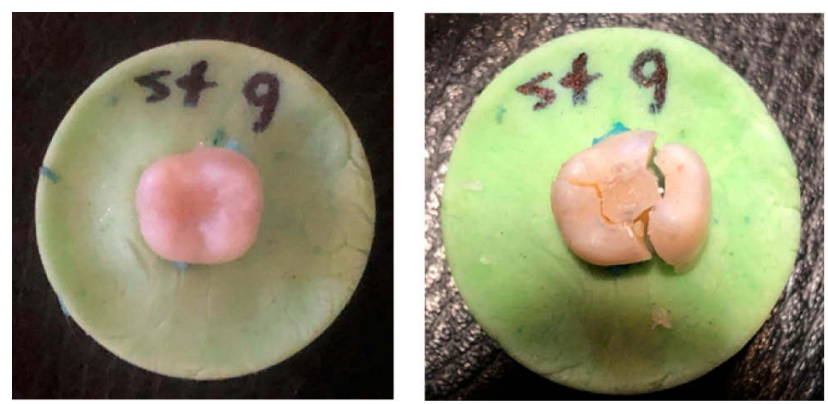

C TREC

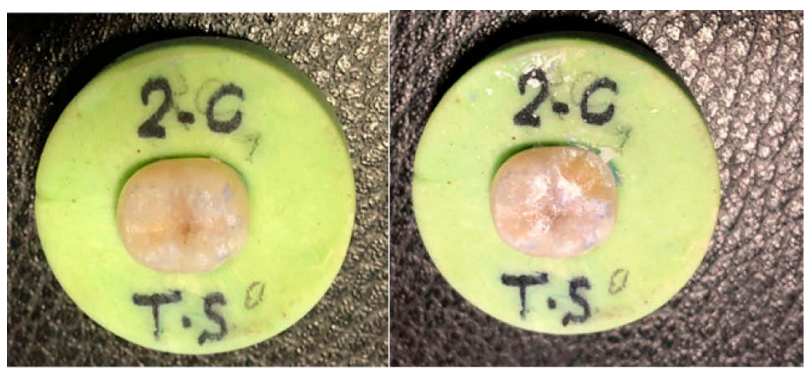

Figure 3 Photographs of the broken teeth in different groups of (A) control, (B) TEC, and (C) TREC.

TEC and TREC designs such that minimum fracture strength was noted in TEC-TC group. However, $t$-test showed no significant difference in fracture strength of the control (with/without thermocycling) and TREC (without thermocycling) groups; whereas, a significant difference was noted between TEC, TEC-TC and TREC-TC groups (Table 1).

\section{Discussion}

The prognosis of endodontically treated teeth directly depends on the amount of remaining tooth structure and strength of the final coronal restoration. ${ }^{22}$ Thus, root canal treatment is not completed until a permanent coronal restoration is placed. Dentin loss is an important factor that adversely affects the survival of endodontically treated teeth. ${ }^{20,21}$ Endodontic treatment steps include preparation of access cavity and instrumentation of the root canal system, which may result in excessive loss of the tooth structure and subsequently lead to weakening of the tooth and its consequently decreased fracture strength against loads. ${ }^{23,24}$

Recently, TREC design was suggested as an alternative to the TEC design since the former better preserves the tooth structure and does not compromise its strength. The TEC design is believed to excessively remove the tooth structure. ${ }^{25,26}$ However, no consensus has been reached regarding the type of access cavity and final restoration of endodontically treated posterior teeth. Also, controversy exists regarding the clinical significance of this treatment plan. ${ }^{12,13,24,27}$ Search of the literature by the authors yielded no study comparing TEC and TREC designs after thermocycling. Thus, this study evaluated the fracture strength of mandibular molars that underwent endodontic treatment through a TEC or TREC design, were restored with composite resin and subjected to thermocycling.

The results showed that the TREC design had a significant effect on fracture strength of endodontically treated mandibular molars, which was not in agreement with the results of other studies. Platino et al indicated that TREC design did not have a significant effect on fracture strength of endodontically treated teeth. ${ }^{16}$ Moore et al and Özyürek et al found no significant difference in fracture strength between the two access cavity designs, ${ }^{11,28}$ which was not in line with our findings.

Our results revealed that the fracture strength of intact teeth (control group) was similar to that of teeth in the TREC experimental group; this finding was in contrast to the results of studies that showed that fracture strength of intact teeth was significantly higher than that of teeth with TEC and TREC designs. ${ }^{11,28}$ Such controversial results can be due to different methodologies with respect to the type of teeth since previous studies used mandibular first molars ${ }^{19,28}$ or maxillary first molars, ${ }^{17}$ while we used mandibular first and second molars. Presence and type of restorations and the method of fracture testing may also play a role in controversial results.

Although the current results indicated that thermocycling had no significant effect on fracture strength of the control group (intact teeth with no access cavity), it significantly decreased the fracture strength of endodontically treated teeth such that the TEC-TC group showed minimum fracture 
Table I Cross-Sectional Diameters, Buccolingual (BL), Mesiodistal (MD) Diameters (mm) and Comparison of Fracture Loads (N) of the Teeth $(n=10)$

\begin{tabular}{|l|l|l|l|l|l|l|}
\hline Group & N & BL & MD & BL x MD & Fracture (N) (SD) & P value* \\
\hline Con & 10 & 10.017 & 10.956 & 110.0324 & $1616.302^{\mathrm{a}} \pm 106.530$ & $>0.05$ \\
Con-TC & 10 & 10.318 & 11.25 & 116.4863 & $1595.7^{\mathrm{a}} \pm 72.708$ & $1601.2^{\mathrm{a}} \pm 143.073$ \\
TREC & 10 & 10.342 & 11.241 & 116.3963 & $1264.928^{\mathrm{b}} \pm 209.305$ \\
TREC_TC & 10 & 10.286 & 11.397 & 116.254 & $1369.9^{\mathrm{b}} \pm 253.903$ \\
TEC & 10 & 10.264 & 11.328 & 116.5389 & $886.23^{\mathrm{c}} \pm 157.559$ \\
TEC-TC & 10 & 10.16 & 11.007 & 112.2544 & $<0.05$ \\
P value & 60 & $>0.05$ & $>0.05$ & $>0.05$ & $<0.05$ \\
\hline
\end{tabular}

Notes: $P$ value: one-way Anova. $P$ value*: independent $t$ test (compare with TC and without TC). ${ }^{\text {a,b,c }}$ Tukey's test for groups comparison.

Abbreviations: Control, con; Con-TC, control with thermocycling; TREC, truss endodontic access cavity; TREC-TC, truss endodontic access cavity with thermocycling; TEC, traditional endodontic cavity; TEC-TC, traditional endodontic cavity with thermocycling.

strength. Also, our results indicated that thermocycled teeth with TREC (TREC-TC) design had higher fracture strength than the TEC-TC group. Such a difference can be due to further loss of tooth structure in preparation of TEC design compared with TREC and conduction of thermocycling.

It should be noted that in vitro studies have limitations and their results should be interpreted with caution. Load bearing capability of endodontically treated teeth is affected by a number of factors such as the number of adjacent teeth, number of occlusal contacts, the position of tooth in dental arch and apical status of the teeth, which cannot be simulated in vitro. ${ }^{29}$ The method of loading in vitro is also different from the oral clinical setting because the load is static in vitro while it is dynamic in vivo. ${ }^{30}$ Furthermore, a wide variability exists in extracted human teeth. ${ }^{31}$ We tried our best to simulate the periodontal ligament and prevent dehydration and its adverse effects on the teeth during the study by storing the teeth in $100 \%$ humidity during the study period. ${ }^{31}$ Load was applied at $15^{\circ}$ angle relative to the longitudinal axis of the tooth to better simulate the clinical setting. ${ }^{32,33}$ Nonetheless, some other factors such as lateral forces are also present in the oral cavity that cannot be simulated in vitro. Thermocycling has not been performed in previous studies on access cavity design and fracture strength; however, it seems to have a significant effect on fracture strength of endodontically treated teeth. It has been reported that elimination of tooth structure during access cavity preparation causes micro-crazing in the enamel and dentin, ${ }^{34}$ which may expand during thermocycling and decrease the fracture strength of teeth.

On the other hand, the load applied to the tooth crown during extraction may cause micro-crazing with variable depths, that may reach the access cavity due to vibrations generated during access cavity preparation, thermal stresses, applied pressures, and thermocycling (causing shrinkage and expansion of tooth structure) and lead to coronal fracture under occlusal loads in vivo, or load application in vitro. The likelihood of microcracks reaching the access cavity is higher in larger-size access cavities (conventional form), and would further decrease the fracture strength of teeth. In contrast, in conservative access cavity preparation, the pericervical tooth structure is more preserved, and the likelihood of microcracks reaching the access cavity would be lower due to its smaller size, which may be one possible reason for higher fracture strength of teeth with conservative access cavities. The mode of crack and its frequency and location in a certain tooth can be explained based on two parameters, namely 1) the microstructure and micromechanical properties of the human enamel and 2) magnitude and direction of loads applied to the tooth during function. Enamel is a hard but brittle structure composed of enamel prisms. Enamel prisms are completely dense masses of hydroxyapatite crystals embedded in a matrix of protein and water. These prisms are vertically aligned on the dentin surface and extend to the surface. ${ }^{35}$ Close to the dentinoenamel junction, a complex of internal defects is present which is mainly composed of hypo-calcified fissures, known as enamel tufts. They are wavy and filled with a protein-rich fluid. These defects are considered as the source of cracks during heavy or continuous loading. ${ }^{36,37}$ Reduction in fracture strength of the teeth following thermocycling in our study may be due to propagation of cracks following access cavity preparation and presence of enamel tufts, since self-healing does not occur in vitro (unlike in vivo). However, it has been demonstrated that enamel tufts can delay the crack propagation such that when a crack propagates, the enamel tufts are continuously filled with protein-rich fluids that repair the crack. This 
mechanism is known as the self-healing mechanism of the enamel. $^{38}$

\section{Clinical Relevance}

The teeth are subjected to different thermomechanical stresses in the clinical setting. Thus, minimum removal of tooth structure (as low as reasonably accessible) would be ideal. Moreover, conservative access cavity preparation in teeth without extensive caries can enhance the fracture strength of endodontically treated teeth.

\section{Limitations}

Small sample size due to the strict inclusion criteria and difficulty in finding sound teeth with standardized pulp chamber sizes in each group was a limitation of this study, which was overcome by increasing the duration of study to find more eligible samples. Also, we randomly allocated the teeth to the groups to minimize the effect of confounding factors such as dentin age on the results.

\section{Conclusion}

Within the limitations of this in vitro study, the results showed that although the fracture strength of endodontically treated mandibular molars with TREC design was not significantly different from that of sound teeth, thermocycling significantly decreased the fracture strength of teeth with TREC and TEC designs. Future studies are required to assess the fracture strength of teeth with TEC and contracted access cavity designs following thermomechanical cyclic loading.

\section{Acknowledgment}

This study was part of an academic thesis accepted by the Deputy of Research of Dental School, Zahedan University of Medical Sciences.

\section{Disclosure}

The authors report no conflicts of interest in this work.

\section{References}

1. Sedgley CM, Messer HH. Are endodontically treated teeth more brittle? J Endod. 1992;18(7):332-335. doi:10.1016/S0099-2399(06) 80483-8

2. Makade CS, Meshram GK, Warhadpande M, Patil PG. A comparative evaluation of fracture resistance of endodontically treated teeth restored with different post core systems-an in-vitro study. $J A d v$ Prosthodont. 2011;3(2):90-95. doi:10.4047/jap.2011.3.2.90

3. Reeh ES, Messer HH, Douglas WH. Reduction in tooth stiffness as a result of endodontic and restorative procedures. J Endod. 1989;15 (11):512-516. doi:10.1016/S0099-2399(89)80191-8
4. Tang W, Wu Y, Smales RJ. Identifying and reducing risks for potential fractures in endodontically treated teeth. J Endod. 2010;36 (4):609-617. doi:10.1016/j.joen.2009.12.002

5. Patel S, Rhodes J. A practical guide to endodontic access cavity preparation in molar teeth. Br Dent J. 2007;203(3):133-140. doi:10.1038/bdj.2007.682

6. Krishan R, Paqué F, Ossareh A, Kishen A, Dao T, Friedman S. Impacts of conservative endodontic cavity on root canal instrumentation efficacy and resistance to fracture assessed in incisors, premolars, and molars. J Endod. 2014;40(8):1160-1166. doi:10.1016/j. joen.2013.12.012

7. Cheung W. A review of the management of endodontically treated teeth: post, core and the final restoration. J Am Dent Assoc. 2005;136 (5):611-619. doi:10.14219/jada.archive.2005.0232

8. Gluskin AH, Peters CI, Peters OA. Minimally invasive endodontics: challenging prevailing paradigms. Br Dent J. 2014;216(6):347. doi:10.1038/sj.bdj.2014.201

9. Yuan K, Niu C, Xie Q, et al. Comparative evaluation of the impact of minimally invasive preparation vs. conventional straight-line preparation on tooth biomechanics: a finite element analysis. Eur J Oral Sci. 2016;124(6):591-596.

10. Bürklein S, Schäfer E. Minimally invasive endodontics. Quintessence Int. 2015;46(2):119-124. doi:10.3290/j.qi.a33047

11. Moore B, Verdelis K, Kishen A, Dao T, Friedman S. Impacts of contracted endodontic cavities on instrumentation efficacy and biomechanical responses in maxillary molars. $J$ Endod. 2016;42 (12): 1779-1783. doi:10.1016/j.joen.2016.08.028

12. Silva EJNL, Rover G, Belladonna FG, De-Deus G, da Silveira Teixeira C, da Silva Fidalgo TK. Impact of contracted endodontic cavities on fracture resistance of endodontically treated teeth: a systematic review of in vitro studies. Clin Oral Investig. 2018;22 (1):109-118. doi:10.1007/s00784-017-2268-y

13. Silva A, Belladonna F, Rover G, et al. Does ultraconservative access affect the efficacy of root canal treatment and the fracture resistance of two-rooted maxillary premolars? Int Endod J. 2020;53:265-275. doi:10.1111/iej.13219

14. Clark D, Khademi JA. Case studies in modern molar endodontic access and directed dentin conservation. Dent Clin. 2010;54 (2):275-289.

15. Buchanan LS. Everything's changed except the anatomy! Dent Today. 2012;31(9):100,2, 4.

16. Plotino G, Grande NM, Isufi A, et al. Fracture strength of endodontically treated teeth with different access cavity designs. $J$ Endod. 2017;43(6):995-1000. doi:10.1016/j.joen.2017.01.022

17. Zhang Y, Liu Y, She Y, Liang Y, Xu F, Fang C. The effect of endodontic access cavities on fracture resistance of first maxillary molar using the extended finite element method. $J$ Endod. 2019;45 (3):316-321. doi:10.1016/j.joen.2018.12.006

18. Marchesan MA, Lloyd A, Clement DJ, McFarland JD, Friedman S. Impacts of contracted endodontic cavities on primary root canal curvature parameters in mandibular molars. J Endod. 2018;44 (10):1558-1562. doi:10.1016/j.joen.2018.07.008

19. Abou-Elnaga MY, Alkhawas M-BA, Kim H-C, Refai AS. Effect of truss access and artificial truss restoration on the fracture resistance of endodontically treated mandibular first molars. J Endod. 2019;45 (6):813-817. doi:10.1016/j.joen.2019.02.007

20. Bektas ÖÖ, Eren D, Siso SH, Akin GE. Effect of thermocycling on the bond strength of composite resin to bur and laser treated composite resin. Lasers Med Sci. 2012;27(4):723-728. doi:10.1007/s10103011-0958-2

21. Corsentino G, Pedullà E, Castelli L, et al. Influence of access cavity preparation and remaining tooth substance on fracture strength of endodontically treated teeth. $J$ Endod. 2018;44(9):1416-1421. doi:10.1016/j.joen.2018.05.012

22. Morgano SM, Rodrigues AH, Sabrosa CE. Restoration of endodontically treated teeth. Dent Clin. 2004;48(2):397-416. 
23. Assif D, Nissan J, Gafni Y, Gordon M. Assessment of the resistance to fracture of endodontically treated molars restored with amalgam. J Prosthet Dent. 2003;89(5):462-465. doi:10.1016/S0022-3913(02) 52748-7

24. Cobankara F, Unlu N, Cetin A, Ozkan H. The effect of different restoration techniques on the fracture resistance of endodontically-treated molars. Oper Dent. 2008;33(5):526-533. doi:10.2341/07-132

25. Lang H, Korkmaz Y, Schneider K, Raab W-M. Impact of endodontic treatments on the rigidity of the root. J Dent Res. 2006;85 (4):364-368. doi:10.1177/154405910608500416

26. Bremer B, Geurtsen W. Molar fracture resistance after adhesive restoration with ceramic inlays or resin-based composites. $\mathrm{Am}$ J Dent. 2001;14(4):216-220.

27. Rover G, Belladonna FG, Bortoluzzi EA, De-Deus G, Silva EJNL, Teixeira CS. Influence of access cavity design on root canal detection, instrumentation efficacy, and fracture resistance assessed in maxillary molars. J Endod. 2017;43(10):1657-1662. doi:10.1016/j. joen.2017.05.006

28. Özyürek T, Ülker Ö, Demiryürek EÖ, Yılmaz F. The effects of endodontic access cavity preparation design on the fracture strength of Endodontically treated teeth: traditional versus conservative preparation. $J$ Endod. 2018;44(5):800-805. doi:10.1016/j. joen.2018.01.020

29. Siso Ş, Hürmüzlü F, Turgut M, Altundaşar E, Serper A, Er K. Fracture resistance of the buccal cusps of root filled maxillary premolar teeth restored with various techniques. Int Endod J. 2007;40 (3):161-168. doi:10.1111/j.1365-2591.2007.01192.X

30. Yamada Y, Tsubota Y, Fukushima S. Effect of restoration method on fracture resistance of endodontically treated maxillary premolars. Int J Prosthodont. 2004;17:1.
31. Akman S, Akman M, Eskitascioglu G, Belli S. Influence of several fibre-reinforced composite restoration techniques on cusp movement and fracture strength of molar teeth. Int Endod J. 2011;44 (5):407-415. doi:10.1111/j.1365-2591.2010.01843.x

32. Jose Soares C, Roberto Marcondes Martins L, Maria Guardiero Azevedo Pfeifer J, Giannini M. Fracture resistance of teeth restored with indirect-composite and ceramic inlay systems. Quintessence Int. 2004;35(4).

33. Plotino G, Buono L, Grande NM, Lamorgese V, Somma F. Fracture resistance of endodontically treated molars restored with extensive composite resin restorations. J Prosthet Dent. 2008;99(3):225-232. doi:10.1016/S0022-3913(08)60047-5

34. Segarra M, Shimada Y, Sadr A, Sumi Y, Tagami J. Three-dimensional analysis of enamel crack behavior using optical coherence tomography. J Dent Res. 2017;96(3):308-314. doi:10.1177/ 0022034516680156

35. Koenigswald W, Rensberger J, Pretzschner H. Changes in the tooth enamel of early Paleocene mammals allowing increased diet diversity. Nature. 1987;328(6126):150-152. doi:10.1038/328150a0

36. Lee J-W, Kwon J-Y, Chai H, Lucas P, Thompson V, Lawn B. Fracture modes in human teeth. J Dent Res. 2009;88(3):224-228. doi:10.1177/ 0022034508330055

37. Chai H, Lee JJ-W, Lawn BR. Fracture of tooth enamel from incipient microstructural defects. J Mech Behav Biomed Mater. 2010;3 (1):116-120. doi:10.1016/j.jmbbm.2009.08.002

38. Chai H, Lee JJ-W, Constantino PJ, Lucas PW, Lawn BR. Remarkable resilience of teeth. Proc Natl Acad Sci. 2009;106(18):7289-7293. doi:10.1073/pnas.0902466106
Clinical, Cosmetic and Investigational Dentistry

\section{Publish your work in this journal}

Clinical, Cosmetic and Investigational Dentistry is an international, peer-reviewed, open access, online journal focusing on the latest clinical and experimental research in dentistry with specific emphasis on cosmetic interventions. Innovative developments in dental materials, techniques and devices that improve outcomes and patient

\section{Dovepress}

satisfaction and preference will be highlighted. The manuscript management system is completely online and includes a very quick and fair peer-review system, which is all easy to use. Visit http://www.dovepress.com/testimonials.php to read real quotes from published authors.

Submit your manuscript here: https://www.dovepress.com/clinical-cosmetic-and-investigational-dentistry-journal 